\title{
Analysis of Lipid Hydroperoxides and Long-Chain Conjugated Keto Acids by Negative Ion Electrospray Mass Spectrometry
}

\author{
Denise K. MacMillan and Robert C. Murphy \\ National Jewish Center for Immunology and Respiratory Medicine, Denver, Colorado, USA
}

\begin{abstract}
Lipid hydroperoxides are important products of enzymatic processes and autooxidation products of polyunsaturated fatty acids. Analysis of such compounds has proved difficult in the past, but negative ion electrospray ionization mass spectrometry was found to be suitable for direct analysis. Abundant $[\mathrm{M}-\mathrm{H}]^{-}$ions were observed in full scan mode for hydroperoxyeicosatetraenoic (HPETE), hydroperoxyoctadecenoic acid isomers, and 5,12-diHPETE. Loss of water was observed for all species. Collisional activation and tandem mass spectrometry generated unique and characteristic spectra that shared some common features such as loss of small neutral molecules. More importantly, fragment ions that were indicative of the position of the hydroperoxide were observed. Collision-induced decomposition (CID) of $\left[\mathrm{M}-\mathrm{H}_{2} \mathrm{O}^{-}\right.$for the HPETE isomers was found to be virtually identical to the CID mass spectra of the $[\mathrm{M}-\mathrm{H}]^{-}$anions from corresponding keto-eicosatetraenoic acids, which suggests that the hydroperoxide anions decompose via a dehydration intermediate that resembles the keto acid molecular anion. Cleavage of the double bond allylic to the hydroperoxide formed structurally characteristic ions at $m / z 129$ from 5-HPETE, $m / z 153$ from 12-HPETE, and $m / z 113$ from 15-HPETE. Charge-driven allylic fragmentation led to formation of $m / z 203$ from 5-HPETE, $m / z 179$ from 12-HPETE, and $m / z 219$ from 15-HPETE. Mechanisms consistent with the decomposition of stable isotope analogues are proposed for the formation of these and other characteristic ions. These specific decompositions can be used in multiple reaction monitoring to measure picomolar concentrations of hydroperoxides by direct high performance liquid chromatography tandem mass spectrometry. (f Am Soc Mass Spectrom 1995, 6, 1190-1201)
\end{abstract}

\section{$\mathrm{L}$} ipid hydroperoxides are formed by both enzymatic and nonenzymatic processes in biological systems. For example, lipid hydroperoxides are the major initial products of free radical-initiated peroxidation of unsaturated fatty acids [1] with a hydroperoxide moiety allylic to a conjugated diene. Stereospecific hydroperoxides are generated by the actions of lipoxygenases and cyclooxygenases, which include those formed as intermediates in the biosynthesis of lipid mediators such as prostaglandins and leukotrienes [2]. Recently, long-chain conjugated keto acids nominally derived from dehydration of arachidonic acid hydroperoxides have been identified and exhibit significant biological activity [3]. Hydroperoxides are thought to play a role in aging and disease processes [4]; thus their determination as well as that of long-chain keto acids in biological environments is of interest.

Several methods for the determination of hydroperoxides are currently employed, but because of the

Address reprints requests and correspondence to Dr. Robert $C$. Murphy, National Jewish Center for Immunology and Respiratory Medicine, 1400 Jackson Street, Denver, CO 80206. instability of the hydroperoxide moiety, most are indirect or general methods rather than analyses that are sensitive and structurally specific for intact compounds [5-10]. Such techniques do not provide information concerning the identity of individual components of the final mixture and also can be susceptible to the presence of contaminants that enhance peroxidation or hydroperoxide decomposition during the assay.

Identification of specific lipid hydroperoxides can be achieved by using high performance liquid chromatography (HPLC) to separate individual species, which are then detected by UV absorbance [11]. Detection is limited to the low nanogram level. Electroanalytical detection also can be combined with HPLC to identify hydroperoxides [12]. More specific information can be gained with greater sensitivity by coupling HPLC with postcolumn reactors and detection of chemiluminescent [13] or fluorescent products [14]. These methods alone, however, do not structurally identify unknown hydroperoxides.

Analysis of intact hydroperoxides by mass spectrometry has proved difficult, again because the hydroperoxide moiety is thermally labile. For analysis by gas chromatography-mass spectrometry (GC-MS), hy- 
droperoxides are generally reduced to alcohols and then converted to volatile derivatives such as pentafluorobenzyl ethers [15], methyl esters [16], or methyl ester, trimethylsilyl ethers [17]. HPLC coupled with thermospray ionization has been used to identify unknown lipid hydroperoxides and hydroperoxy fatty acids esterified to phospholipids [18] with sensitivity in the nanomole range [19]. Direct chemical ionization mass spectrometry yielded ammonia and isobutane adducts of hydroperoxides that could be detected at $100 \mathrm{pg}$ in the selected ion monitoring mode [20]. This technique required extensive sample handling, as did the methods that employ derivatization, and thus provided ample opportunity for sample loss.

Here, a simple method is presented for direct determination of lipid hydroperoxides and related longchain keto acids compatible with HPLC separation techniques. Negative ion electrospray mass spectrometry generates structurally characteristic spectra from low picogram quantities of intact hydroperoxides and fatty keto acids. Analysis can be performed on samples that are introduced via direct infusion (loop injection) or as the effluent from a HPLC separation. Additionally, mechanisms of formation of structurally significant fragments that enable identification of unknown members of the lipid hydroperoxide and long-chain keto acid families are described.

\section{Experimental}

Eicosanoid standards and potato lipoxygenase (5-LO) were purchased from Cayman Chemical (Ann Arbor, MI). Soybean lipoxygenase (15-LO) was purchased from Sigma (St. Louis, MO). 12-Lipoxygenase (12-LO) was isolated from human platelets [21]. Recombinant human 15-lipoxygenase was the generous gift of Dr. Elliot Sigal (Syntex Discovery Research, Palo Alto, CA).

\section{Synthesis of Labeled Standards}

$D_{\mathcal{s}}$-15-HPETE. Oxygen was bubbled at room temperature with stirring through $1 \mathrm{~mL}$ of $0.1-\mathrm{M}$ phosphate buffer that contained 1-mM ethylenediaminetetraacetic acid, $60 \mu \mathrm{L}$ of $200-\mathrm{mM} \mathrm{Ca}^{2+}, 4-\mu \mathrm{L}$ of $100-\mathrm{mg} / \mathrm{mL}$ egg yolk phosphatidylcholine (Sigma), and $20 \mu \mathrm{L}$ of $0.2-\mathrm{M}$ adenosine 5'-triphosphate. After $20 \mathrm{~min}, \mathrm{D}_{8^{-}}$ arachidonic acid ( $\geq 98 \%$ atom $\mathrm{D}_{8}, 100 \mu \mathrm{g}, 50 \mu \mathrm{g} / \mu \mathrm{L}$ in methanol) and soybean lipoxygenase (20 $\mu \mathrm{L}$, $1 \mathrm{mg} / \mathrm{mL}$ ) were added to the oxygenated buffer. The reaction continued for $5 \mathrm{~min}$ with oxygen over the reaction mixture and was quenched with formic acid $(50 \mu \mathrm{L})$. Lipids were extracted twice with 2 volumes of hexane:ethyl acetate (1:1) and subjected to gradient elution reverse-phase HPLC from $70 \%$ solvent A ( $0.05 \%$ acetic acid adjusted to $\mathrm{pH} 5.7)$ to $55 \%$ B (65:35 acetonitrile:methanol) in $10 \mathrm{~min}$, to $65 \% \mathrm{~B}$ over $15 \mathrm{~min}$, then to $100 \% \mathrm{~B}$ over $15 \mathrm{~min}$. 15-Hydroperoxyeicosatetraenoic acid (15-HPETE) eluted between 33 and 35 $\min$.
$D_{8}$-12-HPETE. Human platelet 12-lipoxygenase (12LO) was isolated in accordance with the method of Nugteren [21]. Oxygen was bubbled through 2-mL $0.1-\mathrm{M}$ Tris- $\mathrm{HCl}, 0.1-\mathrm{M} \mathrm{K}_{2} \mathrm{PO}_{4} \mathrm{pH} 8.2$ buffer for $20 \mathrm{~min}$ at room temperature with stirring, after which $\mathrm{D}_{8}$ arachidonic acid $(200 \mu \mathrm{g}, 50 \mu \mathrm{g} / \mu \mathrm{L}$ in methanol) and 12-LO (500 $\mu \mathrm{L}, 9-\mathrm{mg}$ total protein per milliliter of buffer) were added. The reaction proceeded for $10 \mathrm{~min}$ under oxygen. The labeled 12-hydroperoxyeicosatetraenoic acid (12-HPETE) sample was worked up as described above for $D_{8}-15-H P E T E$.

$D_{s}$-5-HPETE. Deuterium labeling of 5-hydroperoxyeicosatetraenoic acid (5-HPETE) began by oxygenation of $1.0-\mathrm{mL} 0.1-\mathrm{M}$ phosphate buffer $\mathrm{pH} 7.0$, 1-mM EDTA at room temperature for $20 \mathrm{~min}$ with stirring. Potato lipoxygenase (1000 units) and $D_{8}$-arachidonic acid $(100 \mu \mathrm{g})$ were added. After $10 \mathrm{~min}$ reaction time, the labeled 5-HPETE was worked up for analysis by electrospray ionization mass spectrometry (ESI-MS) as described above for 12- and 15-HPETE.

${ }^{18} \mathrm{O}_{2}$-HPETEs. Hydroperoxyeicosatetraenoic acids were labeled with two ${ }^{18} \mathrm{O}$ atoms in the carboxyl moiety by using porcine liver esterase (Sigma) [22]. The enzyme (55 units) was dried under nitrogen, then resuspended in $200-\mu \mathrm{L} \mathrm{H}_{2}^{18} \mathrm{O}\left(97.7\right.$ atom $\%{ }^{18} \mathrm{O}$; Isotec, Miamisburg, $\mathrm{OH})$ at $37^{\circ} \mathrm{C}$. The HPETEs $(10 \mu \mathrm{L}$, $1 \mu \mathrm{g} / \mu \mathrm{L}$ in methanol) were incubated individually for $2 \mathrm{~h}$ with enzyme. The reactions were stopped with addition of formic acid $(50 \mu \mathrm{L})$. The ${ }^{18} \mathrm{O}_{2}$-HPETEs were extracted two times with 2 volumes of hexane:ethyl acetate (1:1), evaporated under nitrogen, and then resuspended in methanol:water (1:1) for analysis by ESI-MS.

\section{Preparation of 5(S), 12(S)-diHPETE}

Recombinant human 15-lipoxygenase $(50 \mu \mathrm{L}, 0.84$ $\mathrm{mg} / \mathrm{mL}$ ) was added to $500-\mu \mathrm{L}$ incubation buffer that contained 5-HPETE $(20 \mu \mathrm{g})$ and allowed to react for 10 min at $37{ }^{\circ} \mathrm{C}$ via our previously described method to convert 5-HPETE into $\mathrm{LTA}_{4}$ by this enzyme [23]. The mixture was acidified with formic acid to stop the reaction. Lipids were extracted two times with two volumes of hexane:ethyl acetate (1:1) and then evaporated under nitrogen. The sample was analyzed by reverse-phase HPLC. Fractions were collected for analysis by ESI-MS.

\section{Mass Spectrometry}

Mass spectrometry was performed on a Sciex (PerkinElmer Sciex, Ontario, Canada) API III ${ }^{+}$triple quadrupole mass spectrometer operated in turbospray mode. Nitrogen was used for all inlet gases other than the collision gas, which was argon. The collision gas thickness for tandem mass spectrometry experiments was $250-300 \times 10^{12}$ molecules $/ \mathrm{cm}^{2}$. The turbospray 
Table 1. Electrospray ionization" mass spectra of lipid hydroperoxides derived from arachidonic and linoleic acids

\begin{tabular}{lcc}
\hline Species & $\begin{array}{c}(\mathrm{M}-\mathrm{H})^{-} \\
\text {(relative abundance) }\end{array}$ & $\begin{array}{c}\left(\mathrm{M}-\mathrm{H}^{-}-\mathrm{H}_{2} \mathrm{O}\right. \\
\text { (relative abundance) }\end{array}$ \\
\hline \hline 5-HPETE & $335(100)$ & $317(40)$ \\
12-HPETE & $335(100)$ & $317(6)$ \\
15-HPETE & $335(100)$ & $317(46)$ \\
9-HPODE & $311(100)$ & $292(0)$ \\
13-HPODE & $311(100)$ & $293(0)$ \\
5,12-HPETE & $367(100)$ & $349(0)$ \\
\hline
\end{tabular}

${ }^{\circ}$ Orifice potential $=40 \mathrm{~V}$.

gas was heated to $400{ }^{\circ} \mathrm{C}$ and optimized at $6 \mathrm{~L} / \mathrm{min}$. The curtain gas flow was $1.2 \mathrm{~L} / \mathrm{min}$ and the nebulizer gas flow was held at $0.6 \mathrm{~L} / \mathrm{min}$. For some experiments, samples $(0.5-1 \mathrm{ng} / \mu \mathrm{L})$ were infused with a syringe pump at rates from 5 to $20 \mu \mathrm{L} / \mathrm{min}$. For other experiments, $1-20-\mu \mathrm{L}$ aliquots of sample solutions were injected into a $20-\mu \mathrm{L}$ loop attached to a HPLC loop injector with 1:1 methanol:water that flowed directly into the mass spectrometer. Flow rates for these experiments ranged from 10 to $250 \mu \mathrm{L} / \mathrm{min}$. Sample concentrations ranged from $100 \mathrm{pg} / \mu \mathrm{L}$ to $1 \mathrm{ng} / \mu \mathrm{L}$. For liquid chromatography mass spectrometry (LC-MS) experiments, hydroperoxides were eluted isocratically with a 45:55 mixture of $\mathrm{pH} 5.7,0.05 \%$ acetic acid and acetonitrile:methanol $(65: 35)$ at a flow rate of 250 $\mu \mathrm{L} / \mathrm{min}$ through a $2-\mathrm{mm} \times 150-\mathrm{mm}$ Phenomenex (Torrance, CA) Ultremex $\mathrm{C} 18$ column. For these experiments, $20-\mu \mathrm{L}$ aliquots of the hydroperoxides at a concentration of $100-250 \mathrm{pg} / \mu \mathrm{L}$ were injected.

\section{Results}

\section{Electrospray Ionization Mass Spectrometry}

The hydroperoxides investigated in this study included the following: 5-hydroperoxyeicosatetraenoic acid (5-HPETE), 12-HPETE, and 15-HPETE (20 carbon tetraenes), 9-hydroperoxyoctadecadienoic acid (9HPODE) and 13-HPODE (18 carbon dienes), and 5,12dihydroperoxyeicosatetraenoic acid (5,12-diHPETE; a 20 carbon conjugated triene). All gave abundant carboxylate anions $\left[\mathrm{M}-\mathrm{H}^{-}\right.$by ESI-MS (Table 1 ). These lipid hydroperoxides did not yield abundant positive ions by ESI-MS under the described conditions. The abundance of the molecular anion was greatest at low orifice voltage settings (40-45 V). For all species studied, little or no characteristic fragmentation was observed at this low orifice voltage setting. Loss of water was observed for all $[\mathrm{M}-\mathrm{H}]^{-}$species at orifice voltage settings in the $55-75-\mathrm{V}$ range. For several HPETE species there was no ions observed that corresponded to $\left[\mathrm{M}-\mathrm{H}-\mathrm{H}_{2} \mathrm{O}\right]^{-}$at $40-\mathrm{V}$ orifice potential (Table 1).

Fragmentation could be induced by increasing the orifice voltage (Table 2). As the orifice voltage in-

Table 2. Abundance of characteristic product ions of hydroperoxide molecular anions at various orifice potentials

\begin{tabular}{llrrrrr}
\hline & \multicolumn{5}{c}{ Relative abundance } \\
\cline { 3 - 6 }$m / 2$ & Ion structure & $40 \mathrm{~V}$ & $45 \mathrm{~V}$ & $55 \mathrm{~V}$ & $65 \mathrm{~V}$ & $75 \mathrm{~V}$ \\
\hline \hline $5-H P E T E$ & & & & & & \\
335 & $\mathrm{M}-\mathrm{H}$ & 100 & 70 & 41 & 10 & - \\
317 & $\mathrm{M}-\left(\mathrm{H}+\mathrm{H}_{2} \mathrm{O}\right)$ & 40 & 100 & 100 & 100 & 100 \\
273 & $\mathrm{M}-\left(\mathrm{H}+\mathrm{H}_{2} \mathrm{O}+\mathrm{CO}_{2}\right)$ & - & - & - & 7 & - \\
203 & $\mathbf{A}^{\mathrm{a}}$ & - & - & - & 24 & 60 \\
129 & $\mathbf{B}$ & - & - & 39 & 33 & 56
\end{tabular}

\section{2-HPETE}

\begin{tabular}{llrrrrr}
335 & $\mathrm{M}-\mathrm{H}$ & 100 & 100 & 100 & 77 & - \\
317 & $\mathrm{M}-\left(\mathrm{H}+\mathrm{H}_{2} \mathrm{O}\right)$ & 6 & 10 & 79 & 48 & 36 \\
273 & $\mathrm{M}-\left(\mathrm{H}+\mathrm{H}_{2} \mathrm{O}+\mathrm{CO}_{2}\right)$ & - & - & 40 & 82 & 82 \\
179 & $\mathrm{C}$ & - & - & 7 & 65 & 43 \\
153 & $\mathrm{D}$ & - & - & 18 & 100 & 100 \\
$15-H P E T E$ & & & & & & \\
335 & $\mathrm{M}-\mathrm{H}$ & 100 & 100 & 100 & 55 & 21 \\
317 & $\mathrm{M}-\left(\mathrm{H}+\mathrm{H}_{2} \mathrm{O}\right)$ & 46 & 18 & 89 & 100 & 33 \\
273 & $\mathrm{M}-\left(\mathrm{H}+\mathrm{H}_{2} \mathrm{O}+\mathrm{CO}_{2}\right)$ & 8 & - & - & 44 & 25 \\
219 & $\mathrm{E}$ & 9 & 7 & - & 27 & 22 \\
113 & $\mathrm{~F}$ & 9 & 7 & - & 94 & 100 \\
\hline
\end{tabular}

Structural designation of lettered ions described in text. 
creased, dehydration and decarboxylation occurred more readily. The molecular ion continued to be observed up to $65 \mathrm{~V}$ for 5 - and 12-HPETE, and up to $75 \mathrm{~V}$ for 15-HPETE. At this orifice potential other ions were observed that were indicative of the hydroperoxide position. For example, ion A (Table 2), formed by vinylic cleavage of the $C_{5}-C_{6}$ bond of 5-HPETE, and ions $C$ and $E$ (Table 2) resulted from analogous cleavages of 12- and 15-HPETE anions, respectively. Ions $\mathbf{B}$, $D$, and $\mathbf{F}$ (Table 2) were formed by cleavage of the double bond allylic to the hydroperoxide group of the 5-, 12-, and 15-HPETE molecular species, respectively. The structures of these ions are described below and were confirmed by stable isotope-labeling tandem mass spectrometry studies.

ESI-MS proved to be a very sensitive method for the detection of lipid hydroperoxides. Data from infused samples were generally acquired at concentrations of $100 \mathrm{pg} / \mu \mathrm{L}$ to $1 \mathrm{ng} / \mu \mathrm{L}$. When as little as $1 \mu \mathrm{L}$ of the 15-HPETE solution that corresponded to $100 \mathrm{pg}(300$ fmol) was injected directly, the 15-HPETE was readily observed, even when full scan data with a flow rate of $250 \mu \mathrm{L} / \mathrm{min}$ were collected.

\section{Electrospray Ionization Tandem Mass Spectrometry}

General characteristics. Collision-induced dissociation (CID) and tandem mass spectrometry of the carboxylate anions of the lipid hydroperoxides produced unique and characteristic spectra that shared some common features (Figures 1 and 2). Product ions observed from all $[\mathrm{M}-\mathrm{H}]^{-}$included those formed by loss of water $(m / z 317$ for the HPETEs, $m / z 293$ for the HPODEs, and $m / z 349$ for 5,12-diHPETE) and loss of $\mathrm{CO}_{2}$ and $\mathrm{H}_{2} \mathrm{O}$ from the carboxylate anion $(m / z 273$ for the HPETEs, $m / z 249$ for the HPODEs, and $m / z 305$ for the diHPETE). Loss of two water molecules from the carboxylate anion was also common to all the species studied and yielded $m / z 299$ from the HPETEs and $m / z 279$ from the HPODEs, but only a minor amount of $m / z 331$ from the diHPETE. The HPETEs also exhibited a small amount of $m / z 255$ that resulted from loss of two water molecules and $\mathrm{CO}_{2}$. Low mass fragments that are characteristic of the carboxylate anion were observed for some species. For example, $m / z 59$ and 71 occurred in the spectra of 5-HPETE and 5,12-diHPETE. More importantly, abundant fragment ions indicative of the unique positions of the hydroperoxide moieties also were observed. Product ion abundances for the HPETEs and their stable isotope-labeled analogues are given in Tables 3-5.

5-HPETE. Collision-induced dissociation of the 5HPETE molecular anion (Figure 1a) gave several characteristic fragments in addition to those produced by the simple losses mentioned in the foregoing text. Cleavage adjacent to the hydroperoxide generated ion A, $m / z 203$ (Scheme I). Two low mass ions-the base peak $m / z 59$ and $m / z 71$-shifted 4 units higher in
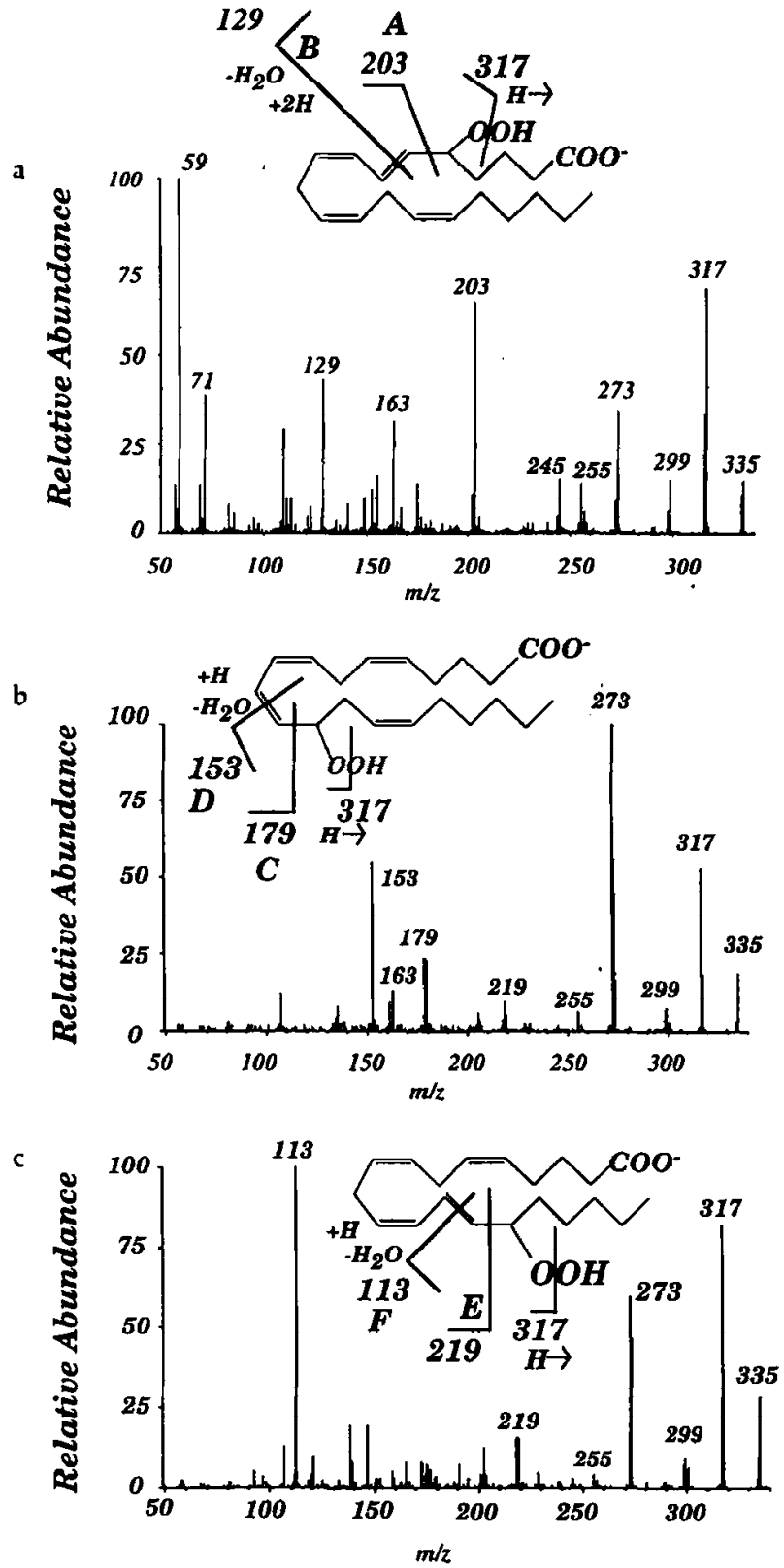

Figure 1. Tandem mass spectrometry following collisioninduced decomposition of the molecular anion $[\mathrm{M}-\mathrm{H}]^{-}$derived from (a) 5-HPETE, (b) 12-HPETE, and (c) 15-HPETE. Collision energy in the laboratory frame of reference was $10 \mathrm{~V}$ with argon as the collision gas.

mass in the CID spectrum of ${ }^{18} \mathrm{O}_{2}$-5-HPETE (Table 3), as did $m / z \quad 317$ and 299 , which indicates that these four fragments retained the carboxylate oxygen atoms. Interestingly, the ion of $m / z 71$ showed only partial incorporation of the ${ }^{18} \mathrm{O}$ label. This suggested a second mechanism of formation that does not include the carboxylate moiety, such as cleavage at $C_{15}-C_{16}$ of the hydrocarbon tail. The only other fragment ion that shifted in mass in the ${ }^{18} \mathrm{O}_{2}-5$-HPETE spectrum was ion B (Scheme I), up 4 units to $m / z 133$ from $m / z 129$ in the spectrum of the unlabeled species. The origin of ion $B$ was consistent with the loss of $\mathrm{H}_{2} \mathrm{O}$ combined 


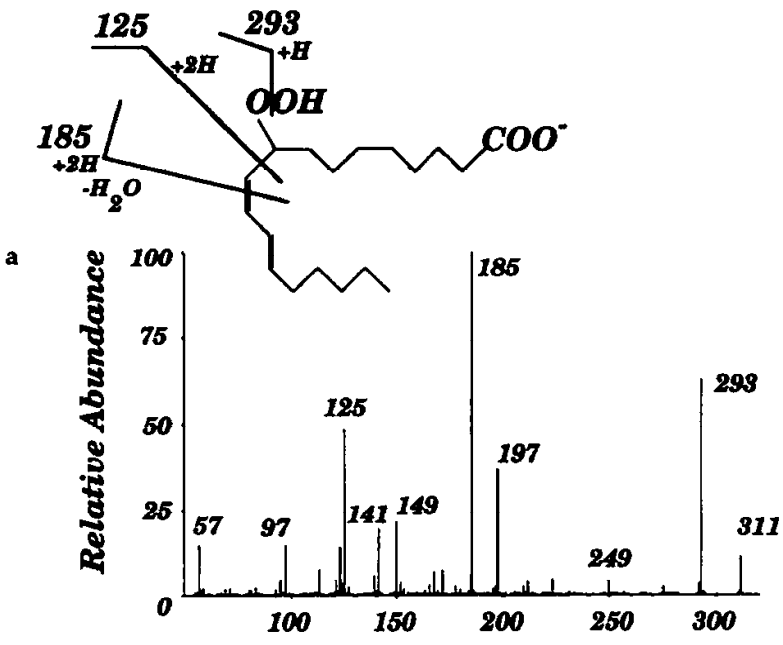

b

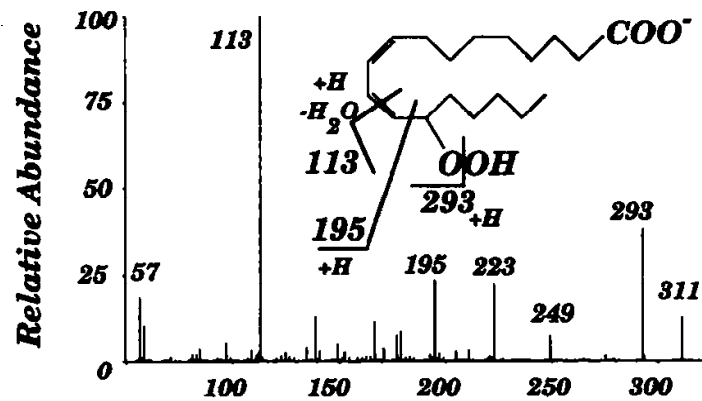

c

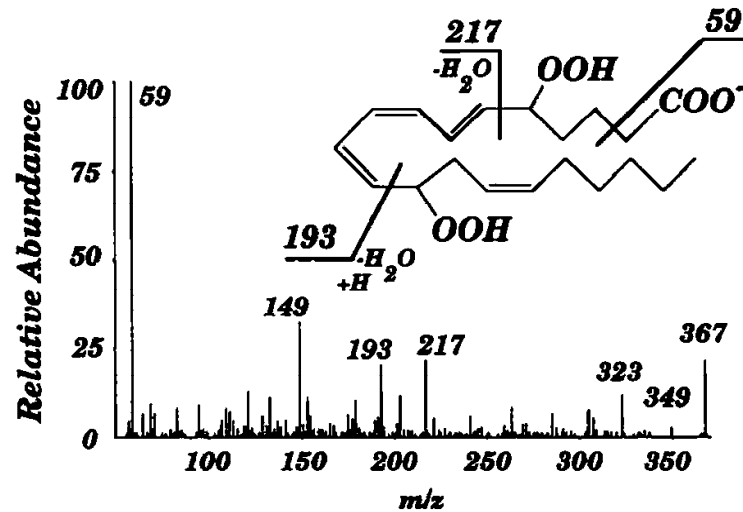

Figure 2. Tandem mass spectrometry following collisioninduced decomposition of the molecular anion of (a) 9-HPODE, (b) 13-HPODE, and (c) 5,12-diHPETE. Collision energy for decomposition of hydroperoxy acids derived from linoleic acid was set at $20 \mathrm{~V}$ and that for the dihydroperoxide was set at $11 \mathrm{~V}$ (laboratory frame of reference).

with an unusual cleavage of the double bond allylic to the point of attachment of the hydroperoxide group. The number of deuterium atoms observed in the CID of $D_{8}-5$-HPETE is consistent with proposed ion structures. For some ions (e.g., $m / z$ 203), other mechanisms of ion formation also were operating (see succeeding text) as revealed by the deuterium-labeling experiments.

The ion of $\mathrm{m} / \mathrm{z} 59$ was characteristic of the $\mathrm{C}_{5^{-}}$ hydroperoxides and is likely due to the facility of attack by the carboxylate anion on a hydrogen attached to $\mathrm{C}_{4}$ after dehydration of the hydroperoxide.
Table 3. Collision-induced decomposition spectra (tandem mass spectrometry) of carboxylate anions derived from 5-HPETE and stable isotope-labeled analogs"

\begin{tabular}{|c|c|c|c|}
\hline \multirow[b]{2}{*}{ Ion structure } & \multicolumn{3}{|c|}{$m / z$ (relative abundance) } \\
\hline & 5-HPETE & $\begin{array}{c}{ }^{18} \mathrm{O}_{2-}^{-} \\
\text {5-HPETE }\end{array}$ & $\begin{array}{c}D_{8^{-}} \\
\text {5-HPETE }\end{array}$ \\
\hline$M-H$ & 335 & 339 & 343 \\
\hline $\mathrm{M}-\left(\mathrm{H}+\mathrm{H}_{2} \mathrm{O}\right)$ & $317(100)$ & $321(57)$ & $\begin{array}{l}325(100) \\
324(45)\end{array}$ \\
\hline $\mathrm{M}-\left(\mathrm{H}+2 \mathrm{H}_{2} \mathrm{O}\right)$ & $299(12)$ & $303(11)$ & $305(6)$ \\
\hline $\mathrm{M}-\left(\mathrm{H}+\mathrm{H}_{2} \mathrm{O}+\mathrm{CO}_{2}\right)$ & $273(21)$ & $273(19)$ & $281(21)$ \\
\hline \multirow[t]{2}{*}{$\mathrm{M}-\left(\mathrm{H}+2 \mathrm{H}_{2} \mathrm{O}+\mathrm{CO}_{2}\right)$} & $255(10)$ & - & $263(5)$ \\
\hline & $245(7)$ & $245(13)$ & $253(7)$ \\
\hline \multirow[t]{4}{*}{$A^{b}$} & $203(32)$ & $203(19)$ & $209(12)$ \\
\hline & & & $210(22)$ \\
\hline & & & $211(15)$ \\
\hline & $163(11)$ & $163(15)$ & $168(8)$ \\
\hline \multirow[t]{5}{*}{$B^{b}$} & $129(19)$ & $133(19)$ & $131(8)$ \\
\hline & $109(9)$ & $109(11)$ & $112(8)$ \\
\hline & $71(12)$ & $75(9)$ & $71(11)$ \\
\hline & & $71(4)$ & \\
\hline & $59(23)$ & $63(17)$ & $59(23)$ \\
\hline
\end{tabular}

a Collision energy in the laboratory frame of reference was $12 \mathrm{~V}$. ${ }^{\mathrm{b}} \mathrm{Structural}$ designation of lettered ions described in text.

Table 4. Collision-induced decomposition spectra (tandem mass spectrometry) of carboxylate anions derived from 12-HPETE and stable isotope-labeled analogs ${ }^{*}$

\begin{tabular}{|c|c|c|c|}
\hline \multirow[b]{2}{*}{ lon structure } & \multicolumn{3}{|c|}{$m / z$ (relative abundance) } \\
\hline & 12-HPETE & $\begin{array}{c}{ }^{18} \mathrm{O}_{2} \\
12-\mathrm{HPETE}\end{array}$ & $\begin{array}{c}\mathrm{D}_{8^{-}} \\
12-\mathrm{HPETE}^{-}\end{array}$ \\
\hline $\mathrm{M}-\mathrm{H}$ & 335 & 339 & 343 \\
\hline $\mathrm{M}-\left(\mathrm{H}+\mathrm{H}_{2} \mathrm{O}\right)$ & $317(52)$ & $321(48)$ & $\begin{array}{l}325(27) \\
324(39)\end{array}$ \\
\hline$M-\left(\mathrm{H}+2 \mathrm{H}_{2} \mathrm{O}\right)$ & 299(7) & $303(4)$ & - \\
\hline $\mathrm{M}-\left(\mathrm{H}+\mathrm{H}_{2} \mathrm{O}+\mathrm{CO}_{2}\right)$ & $273(100)$ & $273(100)$ & $\begin{array}{l}281(54) \\
280(34)\end{array}$ \\
\hline $\mathrm{M}-\left(\mathrm{H}+2 \mathrm{H}_{2} \mathrm{O}+\mathrm{CO}_{2}\right)$ & $\begin{array}{l}255(6) \\
219(9)\end{array}$ & $\begin{array}{l}255(7) \\
219(10)\end{array}$ & $\begin{array}{l}263(17) \\
226(16) \\
225(14)\end{array}$ \\
\hline & $205(5)$ & $205(3)$ & $\begin{array}{l}212(25) \\
211(13)\end{array}$ \\
\hline$c^{b}$ & $179(23)$ & $\begin{array}{l}179(19) \\
183(8)\end{array}$ & $\begin{array}{l}185(76) \\
184(48)\end{array}$ \\
\hline & $163(13)$ & $167(12)$ & $170(17)$ \\
\hline & $161(9)$ & $161(11)$ & $166(35)$ \\
\hline$D^{b}$ & $153(55)$ & $153(59)$ & $\begin{array}{l}158(34) \\
157(100) \\
156(58)\end{array}$ \\
\hline & $135(7)$ & $135(5)$ & $142(28)$ \\
\hline & $107(12)$ & $107(10)$ & $\begin{array}{l}112(18) \\
111(18)\end{array}$ \\
\hline
\end{tabular}

a Collision energy equaled $16 \mathrm{~V}$ (laboratory frame of reference) for $\mathrm{D}_{8^{-1}}$ 2-HPETE and $10 \mathrm{~V}$ for 12 -HPETE and ${ }^{18} \mathrm{O}_{2}-12$-HPETE.

${ }^{b}$ Structural designation of lettered ions described in text. 
Table 5. Collision-induced decomposition spectra (tanden mass spectrometry) of carboxylate anions derived from 15HPETE and stable isotope-labeled analogs"

\begin{tabular}{|c|c|c|c|}
\hline \multirow[b]{2}{*}{ Ion structure } & \multicolumn{3}{|c|}{$m / z$ (relative abundance) } \\
\hline & 15-HPETE & $\begin{array}{c}{ }^{18} \mathrm{O}_{2-}^{-} \\
15-\mathrm{HPETE}\end{array}$ & $\begin{array}{c}D_{8^{-}} \\
15-\text { HPETE }^{-}\end{array}$ \\
\hline$M-H$ & 335 & 339 & 343 \\
\hline$M-\left(H+H_{2} \mathrm{O}\right)$ & $317(82)$ & $321(51)$ & $\begin{array}{l}325(87) \\
324(34)\end{array}$ \\
\hline $\mathrm{M}-\left(\mathrm{H}+2 \mathrm{H}_{2} \mathrm{O}\right)$ & $299(8)$ & $303(5)$ & $\begin{array}{l}305(6) \\
303(5) \\
301(5)\end{array}$ \\
\hline $\mathrm{M}-\left(\mathrm{H}+\mathrm{H}_{2} \mathrm{O}+\mathrm{CO}_{2}\right)$ & $273(60)$ & $273(46)$ & $\begin{array}{l}281(88) \\
280(38)\end{array}$ \\
\hline$E^{b}$ & $219(15)$ & $\begin{array}{l}223(13) \\
219(7)\end{array}$ & $\begin{array}{l}227(13) \\
226(22)\end{array}$ \\
\hline & $203(11)$ & $207(10)$ & $\begin{array}{l}209(10) \\
208(17)\end{array}$ \\
\hline & $191(7)$ & $\begin{array}{l}195(8) \\
191(8)\end{array}$ & $\begin{array}{l}197(8) \\
196(8)\end{array}$ \\
\hline & $173(7)$ & $173(12)$ & $180(26)$ \\
\hline & $165(7)$ & $165(10)$ & $\begin{array}{l}169(9) \\
168(9) \\
167(7)\end{array}$ \\
\hline & $147(19)$ & $147(12)$ & $\begin{array}{l}154(10) \\
153(20) \\
152(23)\end{array}$ \\
\hline & $139(19)$ & $139(27)$ & $\begin{array}{l}142(21) \\
141(30)\end{array}$ \\
\hline & $121(9)$ & $121(10)$ & $\begin{array}{l}126(13) \\
125(9)\end{array}$ \\
\hline$F^{b}$ & $113(100)$ & $113(100)$ & $\begin{array}{l}116(44) \\
115(100) \\
114(82)\end{array}$ \\
\hline & $107(12)$ & $107(8)$ & $113(21)$ \\
\hline
\end{tabular}

a The collision energy (laboratory frame of reference) was $10 \mathrm{~V}$. ${ }^{b}$ Structural designation of lettered ions described in text.

This interaction, which is illustrated in Scheme II, occurs through a six-membered transition state and is inductively enhanced by the electrophilic nature of the $\mathrm{C}_{5}$ carbonyl oxygen of the dehydrated molecular anion. A conjugated ketone neutral molecule and resonance stabilized enolate anion, $m / z 59$, result. Formation of $m / z 59$ is not observed to any great extent for the other hydroperoxides, but is the most abundant product ion from 5,12-diHPETE and is thus considered
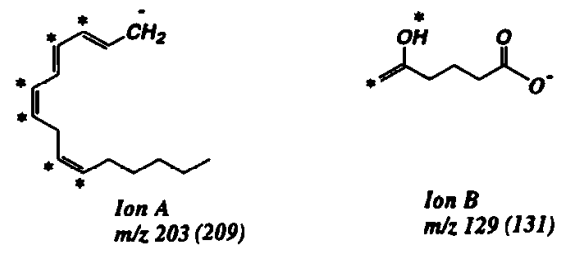

Scheme I

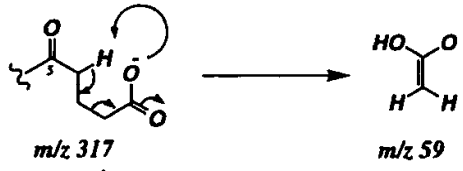

Scheme II

indicative of the hydroperoxy or keto group oxygenation at the $\mathrm{C}_{5}$ position.

Collision-induced dissociation of the $\mathrm{D}_{3}-5$-HPETE anion $(m / z$ 343) obtained from human neutrophils incubated with $D_{g}$-arachidonic acid had many of the fragment ions shifted in mass from that observed for the unlabeled molecular anion. The loss of water observed at $\mathrm{m} / \mathrm{z} 317$ was observed as two ions, $\mathrm{m} / \mathrm{z} 324$ (elimination of $\mathrm{HDO}$ ) and $m / z 325$ (loss of $\mathrm{H}_{2} \mathrm{O}$ ), which suggests that two separate mechanisms lead to dehydration. This phenomenon was observed in the CID mass spectra of both 12-HPETE and 15-HPETE. Scheme III presents two possible mechanisms of dehydration of 5-HPETE where the starting position of each deuterium atom is indicated by the asterisk. The spectrum of the $D_{8}-5$-HPETE anion also showed that the ion of $m / z 203$ shifted to a cluster of peaks: $m / z 209$, 210 , and 211 . The formation of these ions occurred by the allylic fragmentation mechanism discussed later.

12-HPETE. The structurally specific ions $\mathbf{C}$ and $\mathbf{D}$ (Scheme IV), formed by cleavage of bonds in the vicinity of the hydroperoxide position, appeared at $\mathrm{m} / \mathrm{z}$ 179 and 153, respectively (Figure $1 b$ ). In the CID spectrum of ${ }^{18} \mathrm{O}_{2}-12$-HPETE, only a portion of ion $\mathrm{C}$ shifted 4 units, from $m / z 179$ to 183 , which indicated that in one decomposition pathway, the carboxy terminus was retained by the ionized fragment. This ion incorporated five and six deuterium atoms in the $D_{8}$ analog. Ion $D$, formed by cleavage of the $C_{10}-C_{11}$ bond, remained at $m / z 153$, which implied that it did not contain the carboxyl moiety, but it was shifted by three, four, and five deuterium atoms as seen in Table 4 . The only other ion observed to shift mass position in the spectrum of the ${ }^{18} \mathrm{O}_{2}-12$-HPETE anion was $\mathrm{m} / \mathrm{z}$

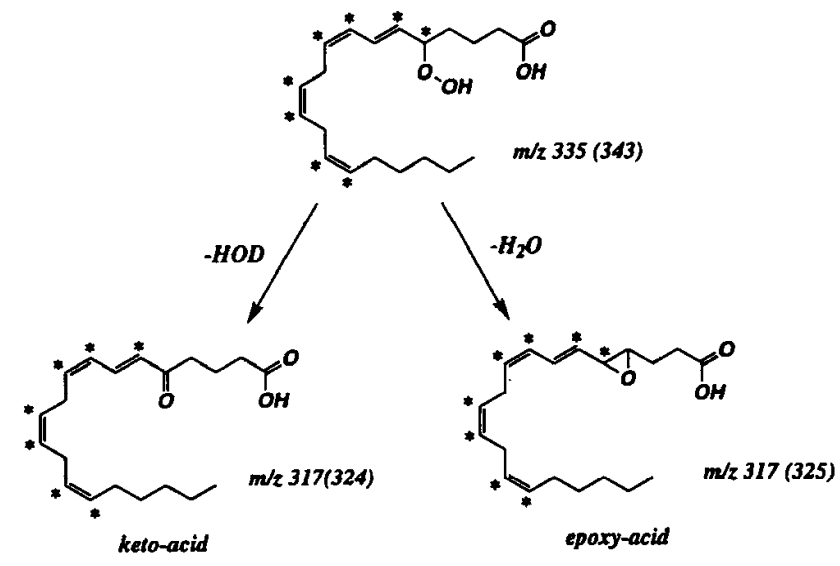

Scheme III 

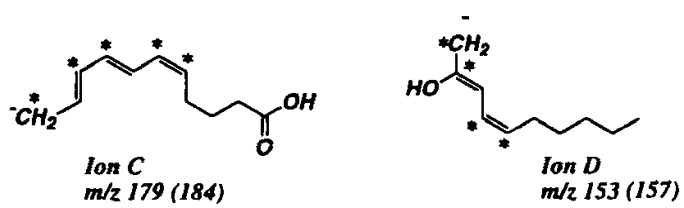

Scheme IV

163 , which incorporated two ${ }^{18} \mathrm{O}$ atoms to become $m / z$ 167. Doublets were observed for several peaks in the spectrum of the $D_{8}-12$-HPETE anion.

15-HPETE. Cleavage of the $C_{14}-C_{15}$ bond of the 15-HPETE (Figure 1c) as suggested for ion $\mathrm{E}(\mathrm{m} / \mathrm{z} 219)$ was shifted to $m / z 223$ in ${ }^{18} \mathrm{O}_{2}$-15-HPETE and to $m / z$ 226 in the $D_{8}-15$-HPETE CID spectra (Scheme V). Interestingly, some $m / z 219$ was still observed in the spectrum of the ${ }^{18} \mathrm{O}_{2}-15$-HPETE species. Breaking the double bond allylic to the hydroperoxide entity and loss of water yielded ion $\mathbf{F}(m / z 113)$-the base peak (Scheme V). This ion did not shift in mass when formed upon CID of ${ }^{18} \mathrm{O}_{2}$-15-HPETE, but occurred as a cluster of three peaks centered around $m / z 115$ in the spectrum of $D_{8}-15$-HPETE (Table 5). A suggested structure for $m / z 113$ is shown in Scheme $V$ consistent with the abundant ion observed at $m / z 114$ in the labeled species.

9-HPODE and 13-HPODE. Collision-induced decomposition of the hydroperoxyoctadecenoic acid (HPODEs) generated fewer product ions than did CID of the HPETEs. The spectra of both 9-HPODE (Figure 2a) and 13-HPODE (Figure 2b) were dominated at high mass by $m / z 293$, the dehydration product ion. Loss of water and cleavage of the double bond allylic to the hydroperoxide moiety gave $m / z 185$ after a two proton shift in the spectrum of 9-HPODE and $m / z 113$ after a single proton shift in the spectrum of 13-HPODE. Cleavage of the $\mathrm{C}_{12}-\mathrm{C}_{13}$ bond of 13-HPODE yielded $m / z 195$ after a single proton shift. The corresponding cleavage of $\mathrm{C}_{8}-\mathrm{C}_{9}$ of 9 -HPODE gave $\mathrm{m} / z 125$ after a two proton shift.

5,12-diHPETE. Collision-induced dissociation of 5,12-diHPETE (Figure 2c) produced $m / z 59$ as the most abundant product ion; vida supra. Cleavage of the double bonds allylic to each hydroperoxide moiety was not observed for 5,12-diHPETE, which suggested a different mechanism of decomposition than that which occurred for the monohydroperoxide carboxyl-

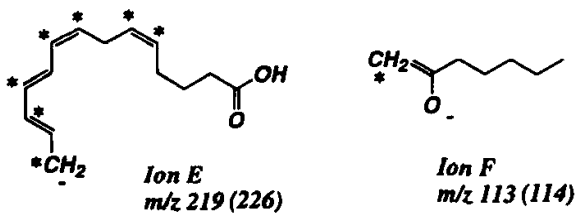

Scheme V ate anions. Fragmentation after dehydration would lead to formation of $m / z 193$ upon cleavage of the $\mathrm{C}_{11}-\mathrm{C}_{12}$ bond and a one proton shift and $m / z 217$ upon cleavage of the $C_{5}-C_{6}$ bond.

Long-chain keto acids. Electrospray ionization mass spectrometry of long-chain keto acids, which corresponds to a dehydration product of the hydroperoxyeicosatetraenoic acids, produced abundant carboxylate anions at $m / z$ 317. Collision-induced decomposition of the carboxylate anions from 5-oxo-eicosatetraenoic acid (ETE), 12-oxo-ETE, and 15-oxo-ETE are shown in Figure 3. The CID spectra of the isobaric ions $(m / z$ 317) derived from dehydration of the corresponding hydroperoxyeicosatetraenoic acids are also shown in Figure 3. Each pair of CID mass spectra had identical product ions with only minor differences in relative abundances between analogous compounds. Typical losses observed from the precursor ion $(m / z$ 317) included loss of water, $\mathrm{CO}_{2}, \mathrm{CO}_{2}$ plus water, and ions unique to each compound pair. For example, the carboxylate anion derived from 5-oxo-ETE produced the same series of fragment ions as did the dehydrated 5-HPETE ion with ion abundances greater for $m / z$ 59, 71,129 , and 255 derived from the 5-HPETE dehydration product ion. The mass spectrum of 12-oxo-ETE and the dehydrated 12-HPETE product ion were also virtually identical. Combined loss of $\mathrm{CO}_{2}$ plus $\mathrm{H}_{2} \mathrm{O}$ occurred to a greater extent from the 12-HPETE fragment ion than did the same loss from 12-oxo-ETE. The only significant difference between 15-oxo-ETE and the 15-HPETE dehydration ion was the greater abundance of $m / z 219$ (ion E) in the CID mass spectrum of the dehydration product of 15-HPETE.

High-performance liquid chromatography-electrospray ionization tandem mass spectrometry. Chromatographic separation and mass analysis of the individual HPETEs was achieved with HPLC-ESI-MS. A mixture of 15 pmol (5 ng) of each HPETE component was injected onto a reverse-phase HPLC column to resolve isomeric hydroperoxides. Detection by ESI-MS provided abundant signals for the carboxylate anion $(\mathrm{m} / z$ 335) of each HPETE when the instrument was operated in the full mass scan mode. By performing multiple reaction monitoring scans, the HPETEs were detected at the 2-ng level. Shown in Figure 4 are the signals obtained by monitoring the transitions from the molecular anions $(m / z 335)$ to ions $\mathbf{B}(m / z 129), \mathbf{C}(m / z 179)$, and $\mathbf{F}(m / z 113)$ after a mixture of 2 ng of each component was injected onto a reverse-phase HPLC column.

\section{Discussion}

Polyunsaturated fatty acids such as linoleic acid and arachidonic acid are some of the most abundant molecules found in biological systems due to the fact that they are major components of the cell membrane 

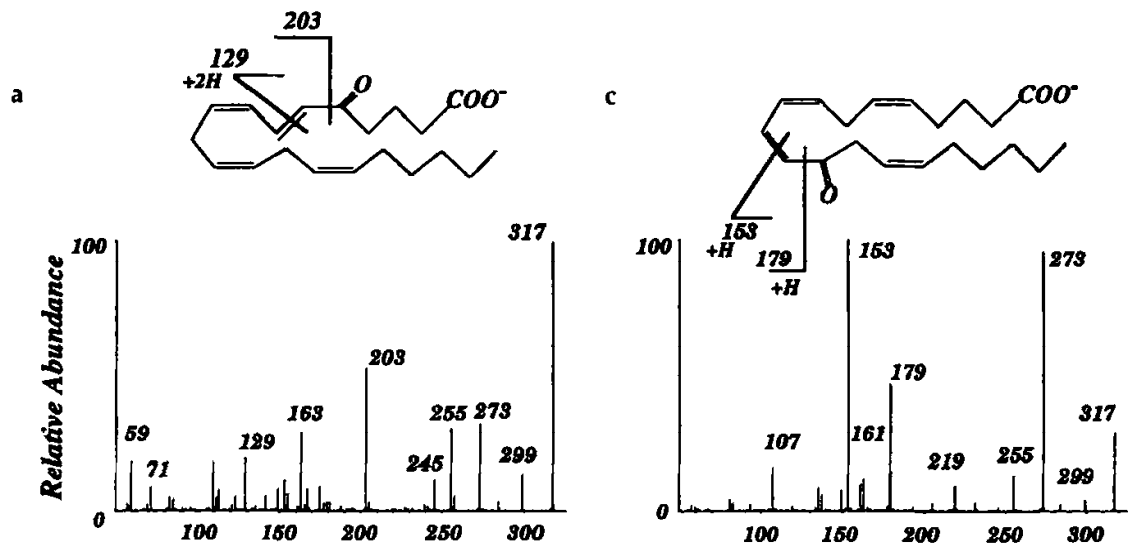

b

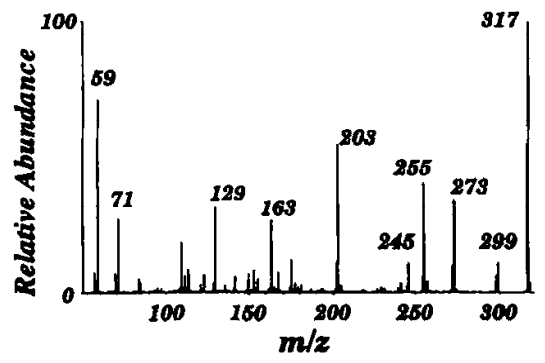

d

$\left((5-H P E T E-H)-\mathrm{H}_{2} \mathrm{O}\right)^{-}$

Figure 3. Tandem mass spectrometry following collision-induced decomposition of $m / z \quad 317$ derived from (a) 5-oxo-ETE carboxylate anion $\left[\mathrm{M}-\mathrm{H}^{-}\right.$, (b) $\left[\mathrm{M}-\mathrm{H}-\mathrm{H}_{2} \mathrm{O}\right]^{-}$from 5-HPETE, (c) 12-oxo-ETE carboxylate anion $\left[\mathrm{M}-\mathrm{H}^{-}\right.$, (d) $\left[\mathrm{M}-\mathrm{H}-\mathrm{H}_{2} \mathrm{O}\right]^{-}$from 12-HPETE, (e) 15-oxo-ETE carboxylate anion $\left[\mathrm{M}-\mathrm{H}^{-}\right.$, (f) $\left[\mathrm{M}-\mathrm{H}-\mathrm{H}_{2} \mathrm{O}\right]^{-}$from 15-HPETE. For all experiments, collision energy was set at $17 \mathrm{~V}$ except in the tandem mass spectra presented in (e), where the collision energy was $14 \mathrm{~V}$. lipid bilayer. A unique structural feature of these long-chain fatty acids is that multiple double bonds are homoconjugated, which results in one or more bis-allylic methylene groups. For example, arachidonic acid has three bis-allylic methylene groups. Removal of a hydrogen atom from such methylene groups by enzymatic or nonenzymatic radical mechanisms in the presence of oxygen leads to the formation of conjugated diene hydroperoxides. These lipid hydroperoxides are not only products of autooxidation of polyunsaturated fatty acids, but also serve as important intermediates in enzymatic reactions that lead to the formation of various lipid mediators, in particular prostaglandins and leukotrienes.

The analysis of such compounds has been somewhat difficult because of their general lability. When attempts were made to analyze these compounds by conventional mass spectrometric techniques such as gas chromatography-mass spectrometry, derivatization reactions resulted in hydroperoxide decomposition [24]. However, electrospray ionization of lipid hydroperoxides yielded abundant molecular anions as shown by several examples in this report. When low orifice potentials $(40-50 \mathrm{~V}$ ) were employed, the abundance of the molecular anion could be optimized and fragmentation of the carboxylate anion could be minimized. These orifice potentials were lower than those used to optimize carboxylate anions of fatty acids, phospholipids, and other eicosanoids, and increasing the orifice potential to $75 \mathrm{~V}$ did increase fragment ion production. Fragment ions that result from dehydration and decarboxylation, which are characteristic of this general class of compounds, were observed during the electrospray process. Above 75-85- $\mathrm{V}$ orifice potential, the carboxylate ion typically was not observed.

Collisional activation of the carboxylate anion generated spectra that included class-specific and speciesspecific product ions. General features observed in the CID tandem mass spectra include loss of water, loss of two water molecules, and loss of water plus $\mathrm{CO}_{2}$. Isotope labeling of the carboxylate oxygen atoms confirmed that the loss of $\mathrm{CO}_{2}$ occurred from the carboxylate moiety whereas the loss of water solely involved the oxygen atom from the hydroperoxide moiety. The mass spectra of the deuterium-labeled HPETEs indicated that this dehydration process occurred via two distinct mechanisms. As depicted in Scheme III for 5-HPETE, loss of the hydroperoxide hydroxyl group and a hydrogen atom from $\mathrm{C}_{4}$ would yield an ion of $m / z 317$ that would retain all deuterium atoms from $\mathrm{D}_{8}-5$-HPETE $(\mathrm{m} / \mathrm{z}$ 325). If the hydroxyl and hydrogen at $\mathrm{C}_{5}$ were lost, dehydration yielded an ion of the same mass $(m / z 317)$, but with a ketone structure that would retain only seven deuterium atoms from $D_{8}-5$ - 

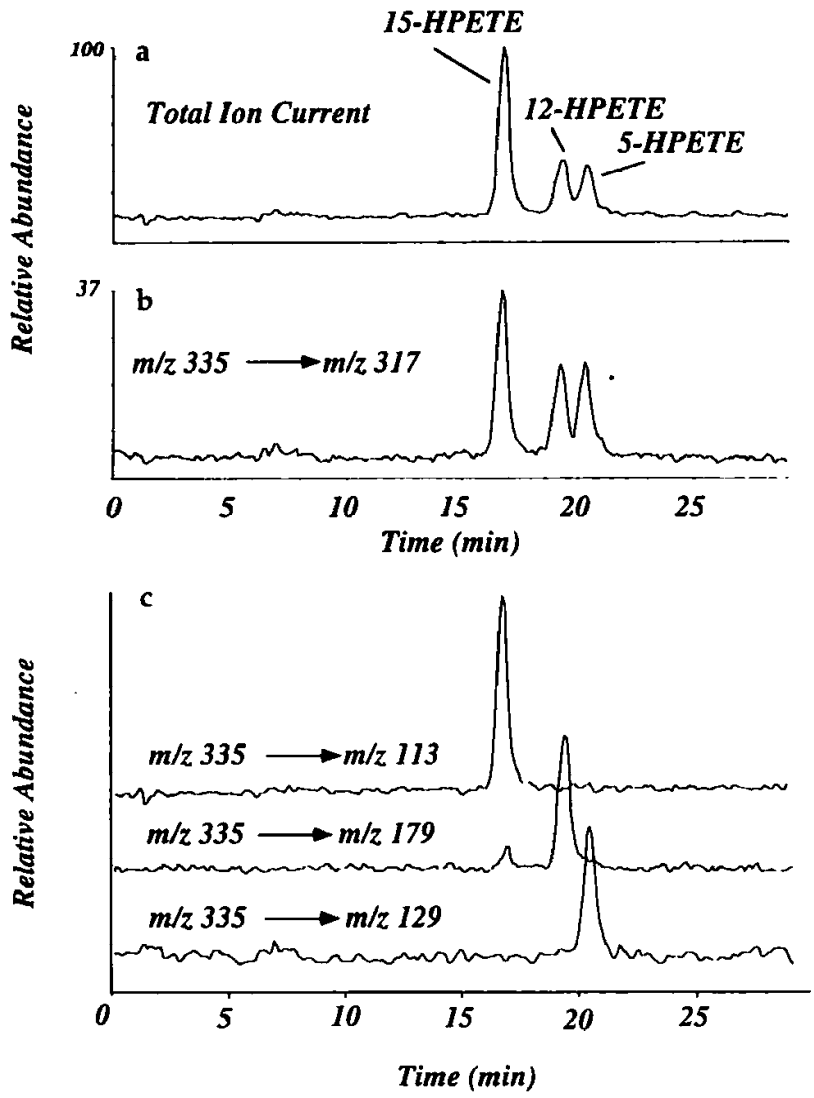

Figure 4. Liquid chromatography tandem mass spectrometry analysis of $5-, 12-$, and 15-HPETE $(m / z 335)$ via reverse-phase HPLC. A mixture of the hydroperoxyeicosatetraenoic acid (2 $\mathrm{ng}$ per component) was injected and then eluted from the $2-\mathrm{mm} \times$ $150-\mathrm{mm}$ C-18 column isocratically $45: 55 \mathrm{pH} 5.7,0.05 \%$ acetic acid): (65:35 acetonitrile:methanol) at a flow rate of $250 \mu \mathrm{L} / \mathrm{min}$. The mass spectrometer was operated in multiple reaction monitoring mode. The collision energy in the laboratory frame of reference was $10 \mathrm{~V}$ with argon as a collision gas at a thickness of 200-300 $\times 10^{12}$ molecules $/ \mathrm{cm}^{2}$. The orifice potential was $40 \mathrm{~V}$. (a) Summation of all ion current for transitions $m / z 335$ to 317 , 113, 179, and 129. (b) Transition for $m / z 335$ to 317 that corresponds to loss of water common to all hydroperoxy acids. (c) Transitions specific for each hydroperoxy acid (individually normalized); see text for description.

HPETE $(m / z$ 324). These two product ions appeared to be in similar abundance. Electrospray ionization and collision-induced decomposition of corresponding long-chain keto acids revealed quite similar, if not identical, decomposition behavior following collisional activation. Considering that both $\mathrm{H}_{2} \mathrm{O}$ and $\mathrm{HDO}$ are lost from deuterium-labeled HPETEs in the dehydration process, the similarity in collision-induced decomposition of $m / z 317$ (Figure 3) suggests that these epoxy acids and keto acids decompose by similar mechanisms.

\section{Double Bond Cleavage}

Each hydroperoxy acid as well as keto acid exhibited product ions, production of which appeared to involve rupture of the carbon-carbon double bond allylic to the hydroperoxide (or keto) position. For example, the ion of $m / z 129$ (ion B) observed in the spectra of 5-HPETE and 5-oxo-ETE would be consistent with cleavage of the $\mathrm{C}_{6}-\mathrm{C}_{7}$ bond. Scheme VI presents a mechanism consistent with the observed mass shifts for the ${ }^{18} \mathrm{O}$ and deuterium-labeled species for each hydroperoxy acid. Loss of HDO to generate a keto moiety at the $\mathrm{C}_{5}$ position (that yields the carboxylate anion of 5-oxo-ETE) followed by rearrangement of one bis-allylic proton from $C_{10}$ via a thermally allowed sigmatropic shift, places a conjugated triene between $\mathrm{C}_{6}-\mathrm{C}_{9}$. A second thermally allowed rearrangement of this 1,3,5-triene would generate a substituted 1,3cyclohexadiene. Formation of such a cyclohexadiene has been suggested to occur in the gas chromatographic column with certain eicosanoid trienes such as $5(S), 12(S)$-diHETE during analysis by GC-MS [25]. Charge-driven attack of the carboxylate anion at the resultant carbonyl carbon at $C_{5}$ would enable abstraction of the bis-allylic proton (deuteron) at $C_{12}$ via a six-membered transition state. Subsequent cleavage of the $\mathrm{C}_{6}-\mathrm{C}_{7}$ bond would result in formation of a neutral substituted benzene and resonance-stabilized anion-ion B at $m / z$ 129. Fragmentations consistent with the mechanism proposed in Scheme VI would account for ion $\mathbf{D}$ from 12-HPETE $(\mathrm{m} / \mathrm{z} 153)$ and ion $\mathbf{F}$ from 15-HPETE $(m / z$ 113). Initiation of these steps from both the epoxy and keto forms of the dehydrated deuterated precursor gives the observed ion distribution.

The collision-induced decomposition spectra of the HPODEs also exhibited ions that result from apparent cleavage of the double bond allylic to the hydroperoxide; specifically the ion of $m / z 185$ from 9-HPODE and the ion of $m / z 113$ from 13-HPODE. These ions would be formed from the dehydration product of the HPODEs after cyclization of the diene into a fourmembered ring, in much the same way that trienes of the HPETEs cyclized into cyclohexadienes. For the dehydrated HPODEs, cyclization would be preceded

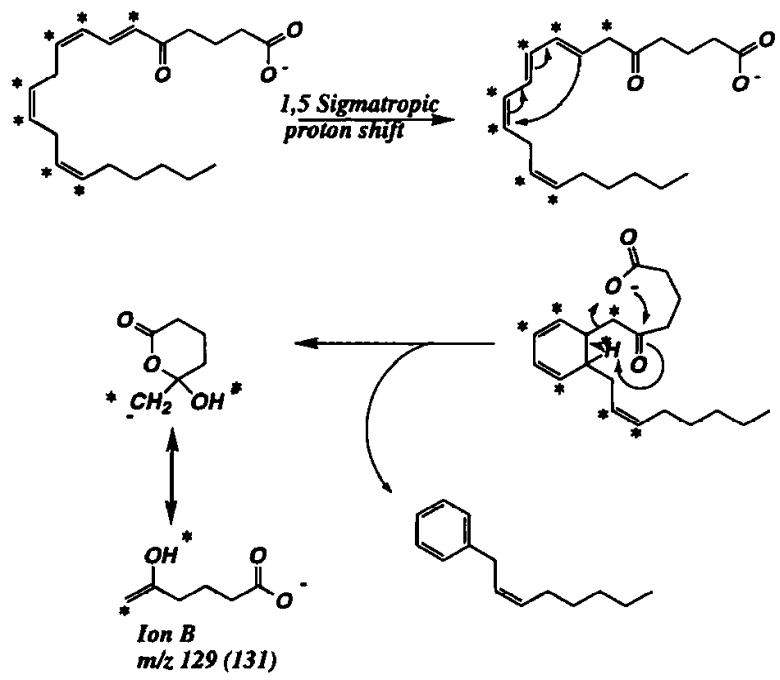

Scheme VI 
by a double bond shift away from the ketone site. Dehydrated 9-HPODE would undergo a diene shift from $C_{10}-C_{13}$ to $C_{11}-C_{14}$. Cyclization would then form a cyclobutane, which joins $C_{11}$ and $C_{14}$. Attack by the carboxylate anion on the carboxyl carbon pushes the negative charge to the carboxyl oxygen, which allows abstraction of the $\mathrm{C}_{14}$ methylene hydrogen through a six-membered transition state and collapses the $C_{10}-C_{11}$ bond to give $m / z 185$, an enolate anion. An analogous pathway for 13-HPODE would form $m / z 113$.

\section{Allylic Fragmentation}

Charge-driven allylic fragmentation was found previously to be a major route for decomposition of hydroxyeicosatetraenoic acids [26]. Evidence for the existence of a similar mechanism was found in the decomposition of the corresponding hydroperoxyeicosatetraenoic acids, which likely proceeds from the dehydrated ion, and corresponds either to the ketone or epoxide structure. As shown in Scheme VII for the dehydration product of 12-HPETE in the ketone form, 1,5-sigmatropic proton rearrangement that leads to a conjugated triene, followed by enolization of the keto group at $\mathrm{C}_{12}$ and abstraction of the resultant hydroxyl proton by the carboxylic anion would lead to an oxonium anion that could undergo the previously described charge-driven allylic fragmentation to yield the ion at $m / z 179$ (ion C). This mechanism is consistent with decomposition of the $\mathrm{D}_{8}$-12-HPETE anion, which is shifted 6 mass units to $m / z$ 185. Charge-driven allylic fragmentation results in abundant formation of $m / z 203$ (ion A) from 5-HPETE and is a second pathway that leads to the generation of ion $\mathbf{E}(m / z 219)$ from 15-HPETE. Initiation of this pathway from both the epoxy and keto forms of the dehydrated precursors generates the multiplets observed in the spectra of the deuterated hydroperoxides.

\section{Unique 5-HPETE Decomposition}

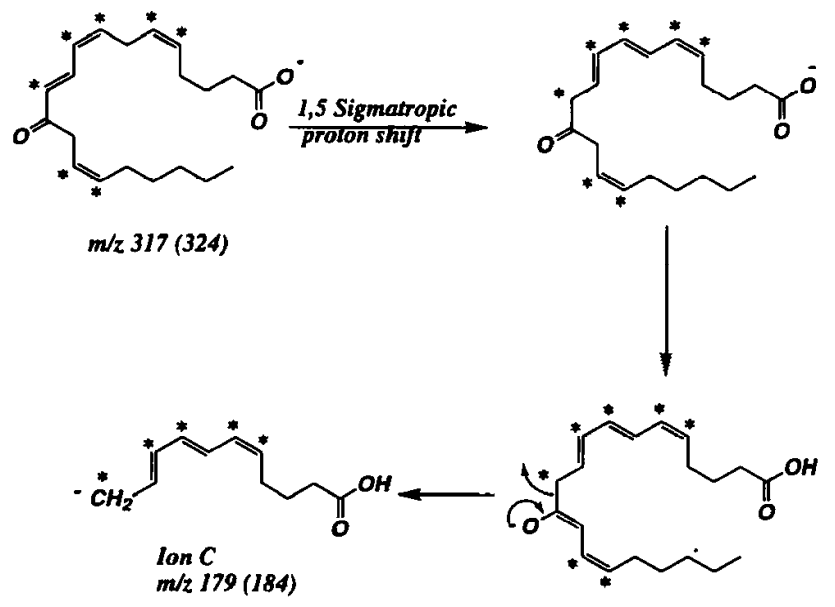

Scheme VII

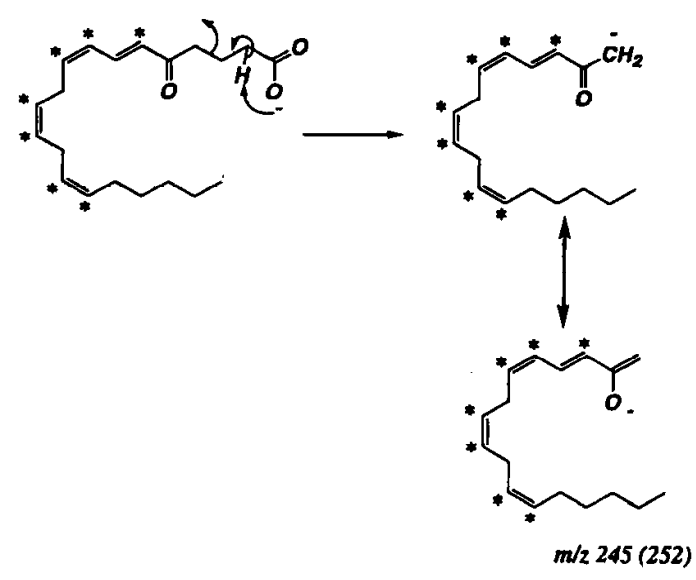

Scheme VIII

The keto or hydroperoxy group situated at $C_{5}$ enhances formation of $m / z 59$ as described previously and also influences formation of $m / z 245$ in the CID spectrum of 5-HPETE. The dehydration product of 5-HPETE $(m / z$ 317) may undergo the fragmentation shown in Scheme VIII to form a highly unsaturated enolate anion, $m / z 245$. This dissociation route begins with abstraction of a hydrogen atom at $C_{2}$ by the carboxylate anion. This rearrangement of the negative charge to $C_{2}$ leads to cleavage of the $C_{3}-C_{4}$ bond and formation of the enolate anion and loss of neutral acrylic acid. A corresponding mechanism was proposed as one decomposition mechanism of 5-HETE [26]. Formation of the $m / z 245$ fragment ion is seen only in 5-HPETE, perhaps because of the possibility of resonance stabilization of the alkoxide anion.

\section{Unique Epoxide Decomposition Ions}

Several ions observed in the tandem mass spectra of the HPETEs could result from rearrangement of the epoxide dehydration intermediate depicted in Scheme III. For example, loss of $\mathrm{H}_{2} \mathrm{O}$ from $\mathrm{D}_{8}$-15-HPETE could yield a 15,16-epoxide as shown in Scheme IX. Rearrangement of the bis-allylic proton at $C_{10}$ would lead to a conjugated triene through a 1,5-sigmatropic shift. A charge-remote proton rearrangement could open the epoxide ring to form the carboxylate anion observed at $\mathrm{m} / \mathrm{z} 219$ and a neutral short-chain aldehyde. Analogous ring openings were observed for lipid epoxides by fast-atom bombardment [27]. In the mass spectrum of ${ }^{18} \mathrm{O}-15-$ HPETE, this ion is observed at $m / z 223$,

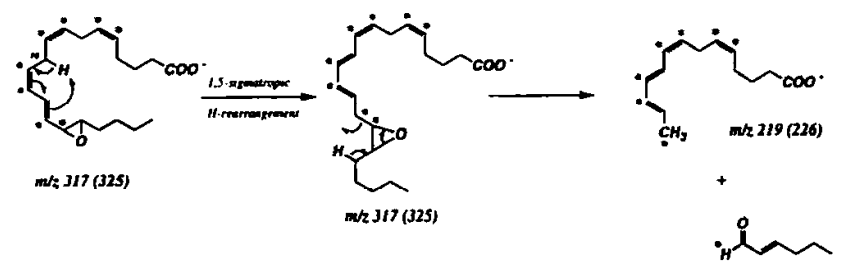

Scheme IX 
which is consistent with the presence of both carboxylate oxygen atoms. Furthermore, in the CID spectrum of $D_{8}-15$-HPETE, the ion is shifted by both 6 and 7 units, which suggests that the proton rearrangement could involve rearrangement of either a deuteron or a proton to $C_{14}$. An analogous charge-remote ring opening of the 4,5-epoxide from dehydrated 5-HPETE only occurs to a minor extent to give the ion of $\mathrm{m} / \mathrm{z} 113$.

Charge-remote ring opening of the 12,13-epoxide of 12-HPETE to generate $m / z 219$ would occur by a slightly different process. Interestingly, 12-HETE also was shown to decompose differently from the other HETEs [26]. A mechanism consistent with the stable isotope data involves a second 1,5-sigmatropic rearrangement. Abstraction of a proton from $C_{11}$ by the $C_{14}-C_{15}$ double bond would lead to formation of a conjugated tetraene carboxylate anion with a terminal aldehyde. The other HPETEs do not have an unsaturated site allylic to the epoxide that cannot shift position to allow the more conventional ring opening and thus not fragment via this modified process.

Both HPODE molecular anions decompose via charge-remote opening of an epoxide, also, but without the 1,5-sigmatropic shift illustrated in Scheme IX. Formation of a $\mathrm{C}_{8}-\mathrm{C}_{9}$ epoxide would occur upon dehydration of the 9-HPODE anion and open with abstraction of $\mathrm{a} \mathrm{C}_{7}$ proton to form a carboxylate anion of $m / z 141$ that contains an omega double bond. Analogous decomposition of 13-HPODE would yield $m / z 223$.

\section{Triene Hydroperoxide}

Collision-induced decomposition of the triene hydroperoxide 5,12-diHPETE produced a distinctive fragmentation pattern. Most abundant in the spectrum was $m / z 59$ which was also the base peak in the decomposition spectrum of 5-HPETE, as previously discussed.

Other abundant ions formed by collision-induced decomposition of the molecular anion highlight the importance of the conjugated system to hydroperoxide fragmentation. The 5,12-diHPETE anion can readily cyclize because the triene is already in place and does not require a preceding 1,5-sigmatropic shift as proposed for the other HPETEs. Scheme $X$ depicts the decomposition of the doubly dehydrated 5,12-di-

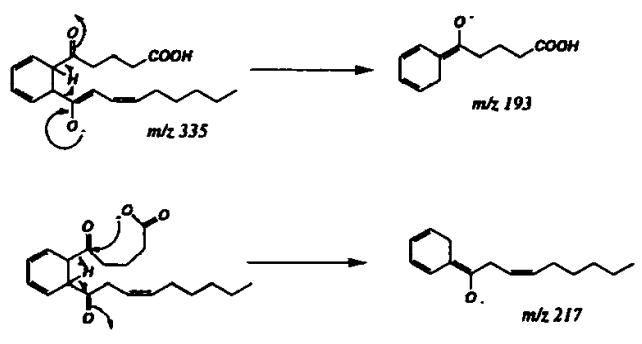

Scheme X
HPETE anion. Enolization of the $C_{12}$ ketone would be favored due to cross-conjugation and would provide a hydrogen for abstraction by the carboxylate anion. Redistribution of the electron density would split the $C_{11}-C_{12}$ bond to form a conjugated ketene neutral molecule and the resonance-stabilized enolate anion, $m / z$ 193. Formation of $m / z 217$, another resonancestabilized enolate anion, would be possible from the same doubly dehydrated, cyclized intermediate. In this instance, however, the attack by the carboxylate anion would occur at the $C_{5}$ ketone to break the $C_{5}-C_{6}$ bond and liberate a small lactone.

The intact triene of 5,12-diHPETE enables facile decomposition by the mechanism outlined in Scheme $X$, but prevents the occurrence of allylic fragmentation of HPETEs (Scheme VII) by fixing the double bond placement. Also, because the 1,5-sigmatropic shift prior to cyclization is unnecessary, 5,12-diHPETE decomposition may not require as much energy. Thus, the dehydrated precursors would have sufficient energy to decompose, which reduces their abundance in the spectrum of 5,12-diHPETE as compared to the HPETEs.

In conclusion, electrospray ionization is a facile technique to generate abundant carboxylate anions from the thermally unstable hydroperoxides derived from polyunsaturated fatty acids. The mass spectra can be obtained without prior derivatization and by direct LC-MS with minimal sample handling. Collisioninduced decomposition of the carboxylate anions results in fragment ions that are indicative of the presence of the hydroperoxy group as well as the position of the hydroperoxide on the carbon chain. The mechanisms of decomposition of the fragment ions induced by collisional activation are consistent with intermediate formation of the keto or epoxide dehydration ions and generally involve rearrangement to highly stable conjugated triene intermediates following 1,5-sigmatropic proton shifts, which is consistent with that previously observed for collision-induced decomposition of both derivatized and underivatized hydroxyeicosatetraenoic acids.

\section{Acknowledgments}

This work was supported, in part, by a grant from the National Institutes of Health (HL25785).

\section{References}

1. Porter, N. A. Acc. Chem. Res. 1986, 19, 262.

2. Samuelsson, B. Soience 1983, 220, 568-575.

3. Powell, W. S.; Zhang, Y.; Gravel, S. Biochemistry 1994, 33, 3927-3933.

4. Gutteridge, J. M. C.; Halliwell, B. Trends Biochem. Sci. 1990, 15, 129-135.

5. Darrow, R. A.; Organisciak, D. T. Lipids 1994, 29, 591-594.

6. O'Gara, C. Y.; Maddipatti, K. R.; Marnett, L. J. Chem. Res. Tox. 1989, 2, 295-300.

7. Buege, J. A.; Aust, S. D. Methods in Enzymology. Vol. 52; Academic Press: San Diego, 1978; p 302. 
8. Recknagel, R. O.; Glende, E. A. Methods in Enzymology, Vol. 105; Academic Press: San Diego, 1984; p 331.

9. Marshall, P. J.; Warso, M. A.; Lands, W. E. M. Anal. Biochem. 1985, 145, 192-199.

10. Burk, R. F.; Ludden, T. M. Biochem. Plammacol. 1989, 38, 1029-1032.

11. Terao, J.; Shibata, S. S.; Matsushita, S. Annl. Biochem. 1988, $769,415-423$.

12. Korytowski, W.; Bahowski, G. J.; Girotti, A. W. Anal. Biochem. 1993, 213, 111-119.

13. Yamamoto, Y.; Brodsky, M. H.; Baker, J. C.; Ames, B. N. Annl. Biochem. 1987, 160, 7-13.

14. Akasaka, K.; Ohrui, H.; Meguro, H. I. Chromatogr. 1993, 628, 31-35.

15. Thomas, D. W.; van Kuijk, F. J. G. M.; Dratz, E. A.; Stephens, R. J. Anal. Biochem. 1991, 198, 104-111.

16. van Kuijk, F. J. G. M.; Thomas, D. W.; Stephens, R. J.; Dratz, E. A. J. Frec Radical Biol. Med. 1985, 1, 215-225.

17. Guido, D. M.; McKenna, R.; Mathews, W. R. Anal. Biochom. 1993, 209, 123-129.
18. Kim, H.-Y.; Salem, R., Jr. Prostnglandins 1989, 37, 105-119.

19. Zhang, J.-R.; Cazers, A. R.; Lutzke, B. S.; Hall, E. D. I. Free Radical Biol. Med. 1995, 18, 1-10.

20. Gut, J.; Trudell, J. R.; Jamieson, G. C. Biol. Environ. Mass Spectrom. 1988, 15; 509-516.

21. Nugteren, D. H. Methods in Enzymology, Vol. 86; Academic Press: San Diego, 1982; p 49.

22. Westcott, J. Y.; Clay, K. L.; Murphy, R. C. Biomed. Mass Spectrom. 1985, 12, 714-718.

23. MacMillan, D. K.; Hill, E.; Sala, A.; Sigal, E.; Shuman, T; Henson, P. M.; Murphy, R. C. J. Biol. Chem. 1994, 269, 26663-26668.

24. Turnipseed, S. B.; Allentoff, A. J.; Thompson, J. A. Anal. Biochem. 1993, 213, 218-225; 1994, 216, 241.

25. Borgeat, P.; Pilote, S. Prostaglandins 1988, 35, 723-731.

26. Wheelan, P.; Zirrolli, J. A.; Murphy, R. C. Biol. Mass Spectrom. 1993, 22, 465-473.

27. Bernstrom, K.; Kayganich, K.; Murphy, R. C. Anal. Biochem. 1991, 198, 203-211. 